\title{
Insufficient evidence to determine the effects of routine scale and polish treatments
}

\author{
Abstracted from \\ Worthington HV, Clarkson JE, Bryan G, Beirne PV. \\ Routine scale and polish for periodontal health in adults. Cochrane Database Syst Rev 2013; 11 : \\ Art. No.: CD004625. DOI: 10.1002/14651858.CD004625.pub4. \\ Address for correspondence: Cochrane Oral Health Group, School of Dentistry, \\ The University of Manchester, Coupland 3 Building, Oxford Road, Manchester, UK. M13 9PL \\ E-mail: cohg@manchester.ac.uk
}

\section{Question: Is routine scale and polish beneficial for oral health?}

Data sources The Cochrane Oral Health Group's Trials Register, the Cochrane Central Register of Controlled Trials (CENTRAL), Medline, Embase, the metaRegister of Controlled Trials and the US National Institutes of Health Clinical Trials Register.

Study selection Randomised controlled trials (excluding split mouth) of routine scale and polish treatments with and without $\mathrm{OHI}$ in healthy dentate adults without severe periodontitis

Data extraction and synthesis Study assessment, data extraction and risk of bias assessment were carried out independently by two reviewers. Mean and standardised mean differences were calculated when different scales were reported. Fixed effects models were used as there were only a small number of studies.

Results Three studies involving a total of 837 patients, and all considered to be at unclear risk of bias were included. No studies reported any adverse effects. Only one trial (conducted in general practice) provided data comparing scale and polish versus no scale and polish. It found no evidence to claim or refute benefit for scale and polish treatments for the outcomes of gingivitis, calculus and plaque. Two studies, both at unclear risk of bias, compared routine scale and polish provided at different time intervals. When comparing six with 12 months there was insufficient evidence to determine a difference for gingivitis at 24 months. There were some statistically significant differences in favour of scaling and polishing provided at more frequent intervals, in particular between three and 12 months for the outcome of gingivitis at 24 months, with $\mathrm{OHI}$, MD - $0.14(95 \% \mathrm{Cl}-0.23$ to $-0.05 ; \mathrm{P}$ value $=0.003)$ and without $\mathrm{OHI} \mathrm{MD}-0.21(95 \% \mathrm{Cl}-0.30$ to -0.12 ; P value $<0.001$ ) (mean per patient measured on 0-3 scale), based on one study. There was some evidence of a reduction in calculus. This body of evidence was assessed as of low quality.

One study provided data for the comparison of scale and polish treatment with and without $\mathrm{OHI}$. There was a reduction in gingivitis for the 12-month scale and polish treatment when assessed at 24

This paper is based on a Cochrane Review published in the Cochrane Library 2013, issue 11 (see www.thecochranelibrary.com for information). Cochrane Reviews are regularly updated as new evidence emerges and in response to feedback, and the Cochrane Library should be consulted for the most recent version of the review. months MD $-0.14(95 \% \mathrm{Cl}-0.22$ to -0.06$)$ in favour of including $\mathrm{OHI}$. There were also significant reductions in plaque for both three and 12-month scale and polish treatments when $\mathrm{OHI}$ was included. The body of evidence was once again assessed as of low quality.

Conclusions There is insufficient evidence to determine the effects of routine scale and polish treatments. High quality trials conducted in general dental practice settings with sufficiently long follow-up periods (five years or more) are required to address the objectives of this review.

\section{Commentary}

This systematic review which has been published in July 2013 on behalf of the Oral Health Group of the Cochrane was first published in $2005^{1}$ and later updated in 2007. ${ }^{2}$ The conclusion has however remained the same in all their revisions. It is presented in the meticulous Cochrane format. In total four objectives are addressed of which for three sufficient evidence was available to result in a conclusion. The body of evidence was graded as being of low quality.

Many dentists and dental hygienists provide scaling and polishing for patients at regular intervals even if those patients are considered to be at low risk of developing periodontal disease. Taking this background premise into account the fourth objective deviates and the comparison to a dentist is broadened to a 'dental care professional', which includes dental hygienist, dental therapist, preventive assistants or preventive nurses. Costa et al. ${ }^{3}$ showed that it is not only the professional but also the setting in which the care is provided. Their results indicate that that periodontal maintenance care provided over 12 months in dental clinics led to significantly less progression of periodontitis and tooth loss as compared to the academic setting.

One of the other objectives the effect of scaling and polishing with and without oral hygiene instruction was evaluated. The review authors could only retrieve one paper relevant to this aspect. However a previous systematic review on controlled studies of at least six months duration showed based on eight papers that an 'oral prophylaxis' delivered at baseline, had a significant, albeit small, positive effect on the reduction of plaque and gingivitis. ${ }^{4}$ Also reference to a review by Needleman et al. ${ }^{5}$ is lacking. These authors investigated the effect of professional mechanical plaque removal on the prevention of periodontal diseases. They concluded based on 39 included papers that there appears to be little value in providing professional mechanical plaque removal without oral hygiene instruction. ${ }^{5}$ 
For the next update of the review it seems worthwhile to take into consideration previous published systematic reviews regarding the topic addressed, and to be more specific about the dental care professional and the setting in which he/she works.

Dagmar Else Slot, Fridus Van der Weijden

Department of Periodontology Academic Centre for Dentistry Amsterdam (ACTA), University of Amsterdam and VU University

Amsterdam, The Netherlands

1. Beirne $\mathrm{P}$, Forgie $\mathrm{A}$, Worthington $\mathrm{HV}$, Clarkson JE. Routine scale and polish for

periodontal health in adults. Cochrane Database Syst Rev 2005; 1: CD004625. Review. Update in: Cochrane Database Syst Rev 2007; (4): CD004625. PubMed PMID: 15674957.
2. Beirne P, Worthington HV, Clarkson JE. Routine scale and polish for periodontal health in adults. Cochrane Database Syst Rev 2007; 4: CD004625. Review. Update in: Cochrane Database Syst Rev 2013; 11: CD004625. PubMed PMID 17943824.

3. Costa FO, Santuchi CC, Lages El, et al. Prospective study in periodontal maintenance therapy: comparative analysis between academic and private practices. / Periodontol 2012; 83: 301-311. doi: 10.1902/jop.2011.110101. Epub 2011 Jul 22. PubMed PMID:21780903.

4. Van der Weijden GA, Hioe KP. A systematic review of the effectiveness of self-performed mechanical plaque removal in adults with gingivitis using a manual toothbrush. / Clin Periodontol 2005; 32: 214-228. Review. PubMed PMID:16128840.

5. Needleman I, Suvan J, Moles DR, Pimlott J. A systematic review of professional mechanical plaque removal for prevention of periodontal diseases. J Clin Periodontol 2005; 32: 229-282. Review. PubMed PMID: 16128841.

Evidence-Based Dentistry (2014) 15, 74-75. doi:10.1038/sj.ebd.6401039 